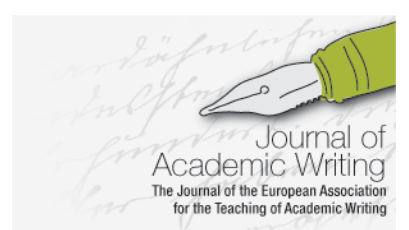 \\ Journal of Academic Writing \\ Vol. No Month Year, pages
}

\section{Intensive Reflection in Teacher Training: What is it Good For?}

\author{
Estela Ene \\ Indiana University - Purdue University, Indianapolis (IUPUI), U.S.A. \\ Cassidy Riddlebarger \\ Indiana University - Purdue University, Indianapolis (IUPUI), U.S.A.
}

\begin{abstract}
The merits of reflective exercises in teacher training are well known. Reflection through journals, surveys/questionnaires, action research, or supervised teaching and classroom discussion creates opportunities for teachers in training to think critically of what they do in their classes, why they do it, and how they could improve. Sometimes, however, teacher training programs may not be ideally positioned to offer novice student teachers (NSTs) the most extensive and coordinated opportunities for teaching, observation, and reflection. The current study examines the usefulness of an intensive reflective exercise realized as a two-question questionnaire used in a Second Language Writing (SLW) course. The findings indicate that the questionnaire was useful in eliciting a fair amount of critical thinking and integration of prior knowledge, new content, and personal experience. For the teacher trainer, it worked as a tool for assessing student learning and planning lessons. The study reflects on the limitations of the intensive reflection exercise applied in it (such as brevity and isolation from other assignments), and makes pedagogical recommendations for future implementation.
\end{abstract}

\section{Background}

Classrooms are busy environments with many inputs and activities occurring throughout the day. As a result, teachers can be unaware of everything happening in their classroom (Farrell 2011). Dewey (1933/1993) first recommended raising teachers' awareness of their own pedagogy through reflection, which he defined as 'the active, persistent and careful consideration of any belief or supposed form of knowledge in the light of the grounds that support it' (9). Reflection, therefore, is a process that helps teachers determine what they are doing, why they are doing it, and what they can do better for the benefit of their students by engaging in some form of process in which they describe, compare, and critically evaluate teaching (Akbari 2007).

Since the 1990s, teacher reflectivity has gained greater focus in the field of teacher training. Researchers and practitioners acknowledge that it is important to understand the benefits of reflection and establish reflective practices during teacher training, given the important ramifications for the subsequent improvement of teaching and learning. Overall, the literature commends teacher reflection for many pedagogical benefits, for both novice (pre-service, student) and experienced professionals. It has been found that it provides teachers with a new model for their teaching (Schön 1983), allows teachers to maximize the learning potential in their classroom (Kumaravadivelu 2003), helps teachers relate their beliefs to classroom practices (Farrell 1998, 2006), provides additional learning experience and autonomy to the teachers (Cole et al 1998), and helps teachers establish their own identity (Brown 2006). It also gives them a chance to focus on their own weaknesses (Farrell 2011 and Geyer 2008), connect the theories of language teaching with language learning (Flowerdew 1998, Geyer 2008, Kwo 1996 and Lee 2010), and focus their teaching (Lee 2007 and Lazaraton and Ishihara 2005). It can aid teachers, especially new ones,

This is the author's manuscript of the article published in final edited form as:

Ene, Estela, and Cassidy Riddlebarger. "Intensive Reflection in Teacher Training: What is it Good For?." Journal of Academic Writing 5.1 (2015): 157-167. http://dx.doi.org/10.18552/joaw.v5i1.160 


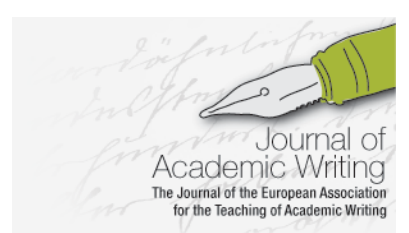

Journal of Academic Writing

Vol. No Month Year, pages

critically assess their beliefs and practices (Brown 2006, Farrell 1998, Farrell 2006, Farrell 2011 and Numrich 1996). In addition, through reflection, teachers become actively engaged in their training and the formation of their own education. Cole et al. (1998) surmise that 'without a personal stake in their preparation, future teachers may simply mimic the current and widely accepted standards and practices of teaching methodologies' (567).

Pedagogical researchers have studied the use of reflection with various types of teachers, including:

- Pre-service teachers (Brown 2006, Cole et al. 1998, Farrell 2008, Flowerdew 1998, Kwo 1996, Lee 2007 and Liou 2000)

- In-service teachers (Farrell 1998, Farrell 2006, Farrell 2011, Geyer 2008, Lee 2010, McDonough 2006, Numrich 1996 and Stanley 1998)

- $\quad$ Novice teachers (Farrell 2011, McDonough 2006 and Numrich 1996)

- Experienced teachers (Farrell 2006, Lazaraton and Ishihara 2005 and Stanley 1998)

- Native-speaking teachers of the target language (Farrell 1998 and Numrich 1996)

- Non-native speaking teachers (Farrell 1998, Farrell 2006 and Liou 2001)

- Teachers in foreign language contexts (Farrell 1998, Farrell 2006, Farrell 2011 and Flowerdew 1998)

- Teachers in second language contexts (McDonough 2006, Numrich 1996 and Stanley 1998)

- Teachers in a TESOL methodology course (Borg 2011, Cole et al 1998, Farrell 2008, Flowerdew 1998, Geyer 2008, Kwo 1996, Lazaraton and Ishihara 2005, Lee 2007, Lee 2010, Liou 2001, McDonough 2006 and Wallace 1996)

- Teachers of second language writing (Farrell 2006 and Lee 2010)

Many reflective practices have been studied as well. These include the use of action research (Kwo 1996, McDonough 2006 and Wallace 1996), teacher narrative and dialogue journals (Cole et al. 1998, Farrell 1998, Flowerdew 1998, Lee 2007, Numrich 1996 and Stanley 1998), surveys/questionnaires or interviews (Brown 2006, Lee 2010 and Stanley 1998), and the observation and evaluation of teachers' own classroom practices (Farrell 1998, Farrell 2006, Farrell 2008, Farrell 2011, Geyer 2008 and Liou 2000). Some studies use elaborate designs. For example, Lazaraton and Ishihara (2005) combined microanalysis and selfreflection, while Geyer (2008) used both micro- and macro-teaching reflections, and Farrell (1998) implemented field notes, group meetings, classroom observations, reaction journals and analysis. In her seminal article, Stanely (1998) proposes a rich model for sustained reflection consisting of five phases of reflective teaching: engaging with reflection, thinking reflectively, using reflection, sustaining reflection, and practicing reflection (590).

Generally, there seems to be an assumption in the research that extensive or elaborate reflective exercises can and should be implemented no matter the context. In addition to complicated or lengthy designs (mentioned above), most of the implementations also heavily involve the teacher trainer and even peers in scaffolding the reflective process. The research has not looked at the effects of reflective practices in which teachers or teacher students share their own insights and analyze their own actions with little or no direct response from a facilitator, who may be balancing a rich teaching agenda. The literature acknowledges that it is difficult to implement extensive reflective exercises over a long period of time, where the teachers in training may disengage when faced with the added workload brought upon by the reflections themselves (Lee 2007and Liou 2001). In addition to possibly resenting the extra work, teachers in training may also have a limited theoretical and practical background, the duration of their training may be short, or the opportunities for teaching practica to reflect upon may be limited. A second gap in the research is related to the fact that most of the existing studies focus on teacher reflection in the context of language teaching methodology courses. We should not forget that a teacher's education is the product of learning from many other related courses as well as personal experience. More research is needed to show whether reflection can be beneficial when used intensively rather than extensively and in courses about other than 


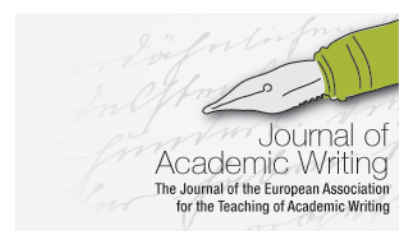

Journal of Academic Writing Vol. No Month Year, pages

\section{TESOL/ELT methodology or practica.}

The goal of this action research study is to explore the usefulness and practicability of reflection in a onesemester course focused on Second Language Writing (SLW). In order to gain insights in the usefulness of reflection, the study poses the following research questions (RQs):

1) What (topics or issues) do novice student teachers (NSTs) of SLW reflect upon when an intensive rather than extensive reflective exercise is implemented?

2) Do the intensive reflections of NSTs display critical thinking?

After presenting the findings based on the data collected in the SLW course, the study will reflect on the merits of the reflective exercise for both the NSTs and the designer of the SLW course.

\section{Context}

The action research presented in this study occurred in a SLW course approved for undergraduate and graduate students at a large university in the U.S. Midwest. The course was offered for the first time when the study was conducted and six students enrolled. The goal of the course was to provide instruction about theories and pedagogies of SLW. The pedagogical training of the NSTs is provided primarily through TESOL methods and materials design courses. Teaching observations or demonstrations are not usually required in courses other than the TESOL methods course because the community is not rich in venues where these can be accomplished. Within the TESOL certificate or MA program, the SLW is an elective that falls in the middle of the sequence of courses. It is open to graduate students from other MA tracks, such as writing and literacy and general English studies, as well as students majoring in Education (second language or general), and undergraduate students. This sets up the course for receiving a heterogeneous student population with varied degrees of preparation and pedagogical experience, which have to be addressed in the course design.

Indeed, from among the six NSTs enrolled in the SLW course, one TESOL certificate student was teaching ESL for the first time, but she was not teaching SLW. Two were completing their teaching practicum in a SLW course, and conducted regular class observations of an experienced teacher whom they assisted with grading tasks. They also participated in supervising group activities in the class and had to teach one or two classes on their own by the end of the semester, with guidance from the practicum mentor. Another NST was an undergraduate student in Writing and Literacy who had no teaching experience at all. Another NST and graduate student in English had taught language arts in the public school system (K-12) in the past but had no prior TESOL training. Overall, the teaching experience among the NSTs in the SLW course was minimal and the opportunity to observe others teaching or practice teaching was limited. The time of the students outside of class was extremely limited as well. They all worked part- or full-time, had families, or - in the case of the undergraduate student - carried a full academic load. Under the circumstances, the lead researcher/course instructor had to design the course in a way that would provide the theoretical preparation about SLW and prepare the students for future teaching without requiring additional class observations, while at the same time trying to make the best of the small amount of teaching experience that the students already had. The instructor believed it was important to create opportunities for the NSTs to think about their own learning, as well as integrate their new knowledge about SLW with knowledge gained in other courses and contexts, or in their own teaching where this was available. Given the positive tone of the research on reflection, it seemed appropriate to build reflective exercises into the course schedule.

Much had to be accomplished in the SLW course to provide the students a theoretical foundation in SLW and prepare them for future teaching. The 14-week semester covered the following topics: 


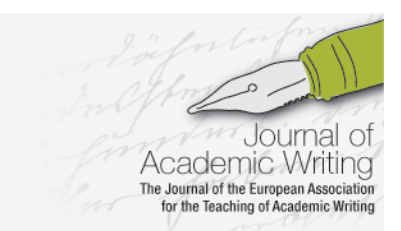

Journal of Academic Writing Vol. No Month Year, pages

- Fundamentals: Defining second language writing and writers

- Pedagogy: Approaches to teaching SLW

- Pedagogy: Syllabus design and lesson planning

- Pedagogy: Feedback and assessment

- Pedagogy: SLW in ESL and EFL contexts

- Pedagogy: Technology and SLW

In take-home written assignments, the NSTs were asked to:

- Write an autobiography of SLW (in week two)

- Conduct a case study of an ESL writer, from needs assessment to designing customized assignments for that learner (in stages, in week three through eight)

- $\quad$ Contribute and present notes on the weekly readings

- Write a final critical review/library research paper on a self-selected topic (in week 13 and 14)

In-class written reflections were built into the schedule in order to raise the NSTs' awareness of their own learning, give them an opportunity to create links between theory and practice (as predicted by the literature above), and monitor learning. In the context of a course that had to cover a lot of theoretical terrain and expose the students to applications of those theories, there was not much space left for extensive in-class reflections. Besides, extensive reflection was used in the autobiographical take-home assignment. The instructor anticipated that intensive reflections might focus the NSTs enough on important issues in SLW or possible topics to pay attention to in their case study and final paper, while not impinging on the time that had to be dedicated to all the other material and tasks.

\section{Data Collection and Analysis}

The instrument chosen to elicit the NSTs' reflections was a two-item questionnaire. Questionnaires have been used, sometimes in conjunction with interviews, to explore teacher development and the gap that exists between teacher beliefs and practice (Brown 2006, Lee 1998, Lee 2010 and Stanley 1998). This form of inquiry seemed therefore promising. The brevity of the questionnaire was intentional, not for the purposes of this action research, but primarily because of the inexperienced group of NSTs and the need to fit the reflection into an already rich schedule. The NSTs' background also dictated the nature of the questions, which could be seen as regular by an expert, but whose primary goal was to support the NSTs learning and self-awareness rather than a research goal. One of the merits of the instrument used is that it was naturally integrated in the teaching process rather than manipulated for research purposes. The questions were:

1) What have you learned from this week's course readings and discussion that was surprising to you? Elaborate.

2) What preconceived idea (or myth) about SLW and writers has been reinforced or shattered through the week's readings and discussion?

The SLW course met twice a week for one hour and fifteen minutes each time for fourteen weeks. The questionnaire was given to the students at the end of each instructional unit. Some units consisted of a single session; others extended over several. For example, extended time was spent on feedback and assessment in SLW. The questionnaire was given a total of seven times during the semester. The students wrote for about 10 to 15 minutes each time. One time, the reflection was assigned as homework because class-time ran out. Forty-two questionnaire responses were collected in all, with each of them consisting of two answers and thus totaling up to a total of eighty-four paragraphs. They consisted of 313 sentences, or 7066 words. 


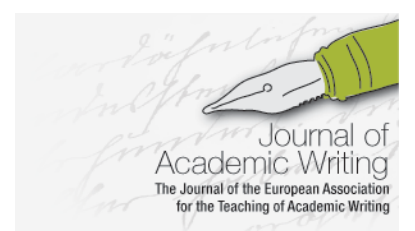

Journal of Academic Writing

Vol. No Month Year, pages

The responses were typed up in a single document and read by the researchers, who identified categories and tallied the comments from each category. The method used for the identification of the themes and their analysis was an adaptation of the procedures used by Liou (2001). The themes emerged from the participants' answers and coincided, for the most part - as expected and natural - with the course topics. Of interest to the researchers was the frequency with which those topics occurred, given that each topic was in focus for only one unit, after which it blended into the discussion without being the primary point. No theme was excluded. Subthemes were identified to distinguish nuances within the main themes. For example, a comment such as 'I was surprised by the emphasis still put on grammar' was placed in the theme of pedagogy, in the sub-theme 'methods and approaches'.

To analyze whether the NSTs' responses were critical, the researchers implemented Liou's (2001) methodology inspired by Ho and Richards (1993). Responses that simply named a topic (for example, 'Today I learned about applications of technology in SLW') were considered descriptive, as were iterations of an expert's opinion or descriptions of a teaching technique. Unlike Liou (2001), we considered statements that linked the NSTs' personal experiences to their readings to be critical in nature, even though they may display only emergent (rather than advanced) critical thinking. For example, the following statement was categorized as critical:

I was surprised at how much culture has to do with the organization of one's writing. I am reading a book right now titled, 1Q84, which was translated into English from Japanese. Through our discussion, I realized that the reason the author has not explained the purpose of the book from the beginning is because it was originally written for a Japanese audience. (Lilly ${ }^{1}$, answer to survey question 1)

Statements in which theories or practices were evaluated, compared, or problematized were coded as critical, too. Even though item 2 in the questionnaire should have yielded mostly critical responses, in the analysis the researchers found that this was not always the case. As will be shown in the Findings section, themes had to be added to the list of course topics to reflect the issues brought up by the participants.

\section{Findings}

This section presents the findings that emerged from the data collected and analyzed as explained above. The findings are reported in two sub-sections corresponding to the study's RQs.

\section{For RQ 1}

As illustrated in Table 1, the NSTs' reflections contained 87 mentions of themes based on both course topics and respondent-generated (sub)themes. Since the compiled reflections amounted to 84 paragraphs, this means that at least one theme was mentioned, on average, in each paragraph generated by the respondents. As expected, the most frequently mentioned theme was related to the theme that dominated the course - pedagogical aspects of SLW; this was mentioned 38, or $43.7 \%$ of the times. The respondents' thoughts on definitions of SLW and writers occurred 21 , or $24 \%$ of the times. Twenty-eight (or $32 \%$ ) of the reflections' themes referred to issues generated by the NSTs, including connections with the role of learners' L1 in SLW, SLA theory, the role of motivation, and connections to personal learning and teaching experiences. Most of the points made by the NSTs were made in response to item 1 of the questionnaire, indicating that the course was useful in teaching them knowledge they had not previously had about SLW, and thus validating the value of the SLW course in the TESOL curriculum.

\footnotetext{
${ }^{1}$ Student names are pseudonyms
} 
The only sub-theme that was mentioned almost twice as frequently in the context of item 2 (about myths contradicted or reinforced) was related to similarities between L1 and L2 writers. Whereas four of the NSTs responses acknowledged learning that differences exist, seven comments indicated shifts from assuming that believing that differences existed to understanding that there are similarities as well, or vice versa. A couple of the seven comments referred to understanding that native and non-native SL writers can be taught together, unlike previously believed by the reflecting NST.

Table 1: Themes from NSTs' responses to the two-item questionnaire

\begin{tabular}{|c|c|c|c|c|c|}
\hline Theme & Sub-theme & $\begin{array}{l}\text { New knowledge } \\
\text { (questionnaire } \\
\text { item 1) }\end{array}$ & $\begin{array}{l}\text { Myth } \\
\text { contradicted or } \\
\text { reinforced } \\
\text { (questionnaire } \\
\text { item 2) }\end{array}$ & $\begin{array}{l}\text { Total } \\
\text { mentions } \\
\text { of sub- } \\
\text { theme }\end{array}$ & $\begin{array}{l}\text { Total } \\
\text { mentions } \\
\text { of theme }\end{array}$ \\
\hline \multirow[t]{5}{*}{ Pedagogy } & $\begin{array}{l}\text { Methods and } \\
\text { approaches in teaching } \\
\text { SLW }\end{array}$ & 13 & 7 & 20 & \multirow[t]{5}{*}{38} \\
\hline & $\begin{array}{l}\text { Syllabus and materials } \\
\text { design (including needs } \\
\text { assessment) }\end{array}$ & 2 & 0 & 2 & \\
\hline & Technology & 6 & 1 & 7 & \\
\hline & Assessment & 4 & 0 & 4 & \\
\hline & Feedback & 4 & 1 & 5 & \\
\hline subtotal & & 29 & 9 & 38 & \\
\hline \multirow{3}{*}{$\begin{array}{l}\text { Fundamentals: } \\
\text { defining SLW } \\
\text { and the SL } \\
\text { writer }\end{array}$} & $\begin{array}{l}\text { SLW as a subfield in its } \\
\text { own right }\end{array}$ & 3 & 1 & 4 & \multirow[t]{3}{*}{21} \\
\hline & Types of learners & 2 & 4 & 6 & \\
\hline & $\begin{array}{l}\text { Similarities between L1 } \\
\text { and L2 writers }\end{array}$ & 4 & 7 & 11 & \\
\hline subtotal & & 9 & 12 & 21 & \\
\hline \multirow{2}{*}{$\begin{array}{lr}\text { Cognitive } & \text { and } \\
\text { linguistic } & \text { SLA } \\
\text { aspects } & \text { of } \\
\text { SLW } & \\
\end{array}$} & The role of L1 transfer & 6 & 3 & 9 & \multirow[t]{2}{*}{10} \\
\hline & L1 attrition & 1 & 0 & 1 & \\
\hline subtotal & & 7 & 3 & 10 & \\
\hline \begin{tabular}{l}
\multicolumn{2}{l}{ Sociocultural } \\
aspects of \\
SLW
\end{tabular} & $\begin{array}{l}\text { Importance of cultural } \\
\text { background }\end{array}$ & 4 & 5 & 9 & 9 \\
\hline subtotal & & 4 & 5 & 9 & \\
\hline \multirow[t]{3}{*}{ Self-reflection } & $\begin{array}{l}\text { On present knowledge } \\
\text { and practice }\end{array}$ & 2 & 1 & 3 & \multirow[t]{3}{*}{8} \\
\hline & On past learning & 2 & 1 & 3 & \\
\hline & On future practice & 2 & 0 & 2 & \\
\hline subtotal & & 6 & 2 & 8 & \\
\hline $\begin{array}{l}\text { Psychological } \\
\text { aspects of } \\
\text { SLW }\end{array}$ & The role of motivation & 0 & 1 & 1 & 1 \\
\hline
\end{tabular}




\begin{tabular}{|c|c|c|c|c|}
\hline subtotal & 0 & 1 & 1 & \\
\hline & & & & $\begin{array}{l}\text { TOTAL } \\
87 \\
\end{array}$ \\
\hline
\end{tabular}

The analysis of the reflections revealed strategies used by the NSTs to make sense of the course content. One set of strategies consisted of connections with the larger field of SLA. Approximately $11 \%$ of the themes raised by the NSTs in their reflections consisted of connections between SLW and SLA theory and sociocultural aspects of SLW - in particular, the importance of a writer's first culture. These topics were pervasive in the readings and class discussions, but they were blended into other topics listed in the syllabus rather than presented as topics per se. It is encouraging that, in their reflections, the NSTs established connections between the object of study and the bigger picture surrounding it.

Another set of strategies consisted of links between SLW and personal opinion or experience. The reflections constituted an opportunity to reflect on one's current knowledge or lack thereof and formulate plans for which approach one will use in the future. For example:

I find that I am discovering more about how I learned both my L1 and L2... Having just thought about my own educational background and upbringing as a writer (for the SLW Autobiography) prior to reading this Chapter, I could recognize various approaches I had experienced, particularly as an L1 writer. (Sandi)

I like the idea of holistic grading now that I know more about it, but for me as a beginning teacher, I think analytic rubrics would be a better choice for now. (Linda)

Overall, it appears that the reflections may not have yielded an outstanding quantity of themes, but served as learning tools to rehash newly acquired knowledge, strengthen connections with the larger field of SLA as well as personal perspectives.

\section{For RQ 2}

Question 2 was meant to elicit critical thinking by asking the NSTs to reflect on shifts in their thinking about SLW. However, most of their answers were descriptive rather than critical (see Table 2). In some answers, the NSTs indicated that they were completely new to SLW and could not think of a preconceived idea related to SLW that they could have changed. In a manner similar to the answers to item 1, they acknowledged learning new information instead.

When critical statements occurred, most of them were evaluative in that they noted the importance of understanding certain issues related to SLW. This type of statement was made with regard to students' cultural background, students' linguistic background, the relationship between learners-teachersinstitutions in needs assessment, addressing different learning styles, providing feedback on multiple drafts, and (not) integrating grammar instruction in SLW classes. A few times, stronger stances were expressed by an NST who 'could not believe the emphasis placed on grammar instruction despite the advances in research,' and another who was 'looking forward to the time when expecting that a one-size-fits-all approach to teaching would be unconscionable.' Three self-reflections made connections between the information learned in the course and enhancing the NSTs' understanding of themselves as readers, writers, and future teachers.

Table 2: Descriptive and critical statements in the NSTs' reflections

\begin{tabular}{|l|l|l|l|}
\hline Theme & Sub-theme & Descriptive & Critical \\
\hline
\end{tabular}




\begin{tabular}{|c|c|c|c|}
\hline \multirow[t]{5}{*}{ Pedagogy } & $\begin{array}{l}\text { Methods and } \\
\text { approaches in teaching } \\
\text { SLW }\end{array}$ & 12 & 8 \\
\hline & $\begin{array}{l}\text { Syllabus and materials } \\
\text { design (including needs } \\
\text { assessment) }\end{array}$ & 2 & 0 \\
\hline & Technology & 7 & 0 \\
\hline & Assessment & 4 & 0 \\
\hline & Feedback & 4 & 1 \\
\hline subtotal & & 29 & 9 \\
\hline \multirow{3}{*}{$\begin{array}{l}\text { Fundamentals: } \\
\text { defining SLW } \\
\text { and the SL } \\
\text { writer }\end{array}$} & $\begin{array}{l}\text { SLW as a subfield in its } \\
\text { own right }\end{array}$ & 2 & 2 \\
\hline & Types of learners & 3 & 3 \\
\hline & $\begin{array}{l}\text { Similarities between L1 } \\
\text { and L2 writers }\end{array}$ & 11 & 0 \\
\hline subtotal & & 16 & 5 \\
\hline \multirow{3}{*}{$\begin{array}{lr}\text { Cognitive } & \text { and } \\
\text { linguistic } & \text { SLA } \\
\text { aspects } & \text { of } \\
\text { SLW } & \\
\end{array}$} & The role of L1 transfer & 6 & 3 \\
\hline & L1 attrition & 1 & 0 \\
\hline & & 7 & 3 \\
\hline $\begin{array}{l}\text { Sociocultural } \\
\text { aspects of } \\
\text { SLW }\end{array}$ & $\begin{array}{l}\text { Importance of cultural } \\
\text { background }\end{array}$ & 4 & 5 \\
\hline subtotal & & 4 & 5 \\
\hline \multirow[t]{3}{*}{ Self-reflection } & $\begin{array}{l}\text { On present knowledge } \\
\text { and practice }\end{array}$ & 2 & 1 \\
\hline & On past learning & 2 & 1 \\
\hline & On future practice & 1 & 1 \\
\hline subtotal & & 5 & 3 \\
\hline $\begin{array}{l}\text { Psychological } \\
\text { aspects of } \\
\text { SLW }\end{array}$ & The role of motivation & 1 & 0 \\
\hline subtotal & & 1 & 0 \\
\hline TOTAL & & 62 & 25 \\
\hline
\end{tabular}

As in the analysis related to $\mathrm{RQ} 1$, it appears that the intensive reflection was not particularly productive in terms of bringing forth much critical thinking. However, some critical thinking was present, and a lot about its absence seems to have to do with the NSTs' self-reported lack of experience. Regardless, the fact that learning occurred - and may have been enhanced by the reflective exercise as suggested in the existing literature - has value in itself.

\section{Discussion and Implications}

Based on the thematic categories identified above, the use of a brief reflective exercise with novice student teachers seems to be productive in some respects but not others. With respect to RQ 1 , the study found 


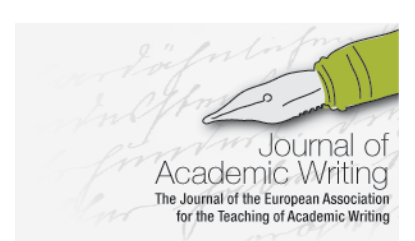

Journal of Academic Writing

Vol. No Month Year, pages

that, in their intensive reflections, NSTs acknowledged that they were acquiring new knowledge about the most important course topics and related nuances; moreover, they connected the new knowledge to the larger SLA context, as well as their own experience as learners and NSTs. With respect to RQ 2, the findings show that little critical thinking occurred in the NSTs' reflections.

There are several reasons why the intensive reflective exercise used in this action research may not have led to more critical responses, even though one of the questions used was designed so as to display the NSTs' critical thinking. First of all, the NSTs' lack of experience with SLW theory and practice was selfreported as an impediment. Second, the design of the exercise may have been too restrictive: the amount of time allotted for it was short, the exercise was usually completed in class, and two questions may not have been enough to trigger deep analysis. Similar design issues have been noted in other studies which managed to demonstrate more critical thinking but not change over time (for example, Borg 2011 and Kwo 1996). The one time that the reflection was assigned as homework, it yielded longer, multi-paragraph responses. It would have been desirable to ask more questions in the questionnaire, or link the reflections to larger assignments. However, the research meant to examine what would happen if the reflection was implemented in a minimalistic way so that it would not take time from classroom discussion, presentations, applications, and the development of the NSTs' research skills. Previous research has worked with extensive reflections through either journals or long surveys (Farrell 2008, Farrell 2011, Lee 2010, Lee 2011 and Geyer 2008). In light of the success of reflective exercises presented in those studies, it seems that one would be better off setting up longer and more intricately connected reflections, possibly outside of class.

The fact that the NSTs' intensive reflections did not lead to a great amount of critical thinking does not mean that the exercise failed. In any research, and particularly in action research, worthwhile secondary findings can surface. In this study, the NSTs may not have benefitted from intensive reflection by gaining critical awareness of SLW. However, the exercise was successful as a self-assessment of learning and a way to consolidate, at the end of each instructional unit, at least one important new nugget of information about SLW. Sources on classroom assessment techniques (CATs) give ample examples of short reflective exercises used to this end. In their seminal work on CATs, Angelo and Cross (1993) list many such techniques whose merit is that they provide just-in-time feedback to both learners and instructors, encourage a view of teaching as an ongoing process of inquiry and reflection, and help students and teachers to monitor progress. Additionally, the use of CATs enhances students' sense that the instructor cares about their learning. As stated above, the reflective exercise/CAT can be redesigned in a number of ways in order to increase its effectiveness at triggering critical thinking, including by rephrasing the prompt or re-sequencing the material.

As a CAT, the questionnaire used in this action research worked well as a low-maintenance formative assessment of recall and immediate learning (and long-term retention of concepts remains to be further explored). Additionally, the intensive reflections had a number of practical and pedagogical benefits for the instructor in charge of the SLW course. The intensive implementation of reflection allowed the course instructor to include reflection in the routine of the course, while also fitting in all the important components of the course - discussions, presentations, research projects, and other applications. Moreover, reading the NSTs' reflections allowed the instructor to better understand the NSTs' knowledge-base for SLW, gauge their learning, and address their areas of need. For example, one of the early topics in the course was related to defining the field of SLW and different types of SL writers. While the instructor expected the NSTs to be unknowledgeable about SLW, she did not anticipate that defining SL writers would be problematic, because the students in the course had been exposed to discussions on diversity and multiculturalism in their respective areas of study and in their life in the U.S. It was surprising that all of the NSTs commented on that they had not been aware that culture could mean much more than ethnic background. After reading the set of reflections in which this statement was made, the instructor had the opportunity to open a classdiscussion that further focused on the meaning of culture and how it could influence one's SLW. This linked to discussions of linguistic transfer, which led to the realization on the part of three of the NSTS that SL 
writers are not always at a disadvantage compared to L1 writers. In future offerings of the SLW course, the instructor can anticipate which topics may attract more interest or need more focused attention; more importantly, the instructor should be prepared to deliver the reflection/CAT with new groups, in a redesigned form, in order to adapt to the needs of each cohort of NSTs. The gaps in knowledge of the NSTs may be context-specific, but the idea that brief reflections can give a course instructor insights into the learners' needs (in a SLW or other course) stands.

The number of participants in this study was small, as is typical of action research on reflection. Additional research is needed to lead to generalizable findings. In a growing body of literature that advocates for extensive reflection, this study shows the usefulness and limitations of intensive, focused reflection with teachers-in-training. This might be the only kind of reflection accessible to those in short teacher training programs, programs with a small but diverse group of participants, and programs in which the limited experience of the participants and the lack of venues for larger-scale exercises restrict the opportunities for reflection and practice. As Stanley (1998) recommends, it is important to create opportunities, at any stage of teacher training, for in-service and pre-service teachers to engage in reflection, and - if possible - to follow up on their reflections with teaching applications. 


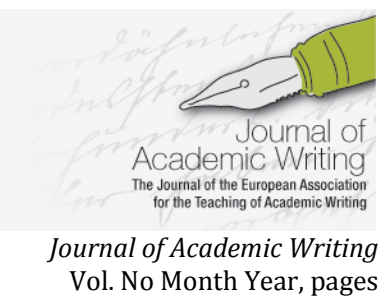

\section{References}

Angelo, T.A., and Cross, K.P. (1993) Classroom Assessment Techniques: A Handbook for College Teachers. Boston: Jossey-Bass.

Akbari, R. (2007) 'Reflections on Reflection: a Critical Appraisal of Reflective Practices in L2 Teacher Education'. Systems 25(2), 192-207.

Borg, S. (2011) 'The Impact of In-service Teacher Education on Language Teachers' Beliefs'. System 39, 370-380.

Brown, J. (2006) 'Dilemmas of Identity in Teacher Education: Reflections on one Pre-service ESL Teacher Cohort'. TESOL in Context 16, 118-128.

Cole, R., Raffier, L. M., Rogan, P., and Schleicher, L. (1998) 'Interactive Group Journals: Learning as a Dialogue among Learners'. TESOL Quarterly 32(3), 556-568.

Dewey, J. (1933/1993) How We Think: a Re-statement of the Relation of Reflective Thinking to the Education Process. Boston: DC. Health, \& Co.

Farrell, T. S. (1998) ‘ESL/EFL Teacher Development through Journal Writing'. RELC Journal 29(1), 92-109.

Farrell, T. S. (2006) 'Reflective Practice in Action: A Case Study of a Writing Teacher's Reflections on Practice'. TESL Canada Journal 23(2), 77-90.

Farrell, T. S. (2008) 'Promoting Reflective Practice in Initial English Language Teacher Education: Reflective Microteaching'. Asian Journal of English Language Teaching 18(1), 1-15.

Farrell, T. S. (2011) 'Keeping Score': Reflective Practice Through Classroom Observations'. RELC Journal 42(3), 265-272.

Flowerdew, J. (1998) 'Language Learning Experience in L2 Teacher Education'. TESOL Quarterly 32(3), 529-536.

Geyer, N. (2008) 'Reflective Practices in Foreign Language Teacher Education: A View Through Micro and Macro Windows'. Foreign Language Annals 41(4), 627-638.

Kumaravadivelu, B. (2003) Beyond Methods: Macrostrategies for Language Teaching. New Haven, CT: Yale University Press.

Kwo, O. (1996) 'Learning to Teach English in Hong Kong Classrooms: Patterns of Reflections'. in Teacher Learning in Language Teaching. ed. by Freeman, D and Richards, J.C. Cambridge: Cambridge University Press, 295-319.

Lazaraton, A., and Ishihara, N. (2005) 'Understanding Second Language Teacher Practice Using Microanalysis and Self-Reflection: A Collaborative Case Study'. The Modern Language Journal 89(4), 529-542.

Lee, I. (1998) 'Writing in the Hong Kong Secondary Classroom: Teachers' Beliefs and Practice'. Hong Kong Journal of Applied Linguistics 3(1), 61-76.

Lee, I. (2007) 'Preparing Pre-service English Teachers for Reflective Practice'. ELT Journal 6(1), 321-329.

Lee, I. (2010) 'Writing Teacher Education and Teacher Learning: Testimonies of Four EFL Teachers'. Journal of Second Language Writing 19, 143-157.

Liou, H. (2001) 'Reflective Practice in a Pre-service Teacher Education Program for High School English Teachers 
in Taiwan, ROC'. System 29, 197-208.

McDonough, K. (2006) 'Action Research and the Professional Development of Graduate Teaching Assistants'. The Modern Language Journal 90(1), 33-47.

Numrich, C. (1996) 'On Becoming a Language Teacher: Insights from Diary Studies'. TESOL Quarterly 30(1), 131153.

Schön, D.A. (1983) The Reflective Practitioner: How Professionals Think in Action. New York: Basic Books.

Stanley, C. (1998) 'A Framework for Teacher Reflectivity'. TESOL Quarterly 32(3), 584-591.

Wallace, M. (1996) 'Structured Reflection: The Role of Professional Project in Training ESL Teachers'. in Teacher Learning in Language Teaching. ed. by Freeman, D. and Richards, J.C. Cambridge: Cambridge University Press, 281-294. 